\title{
Novel Carrier-Based PWM Strategy of a Three-Level NPC Voltage Source Converter without Low-Frequency Voltage Oscillation in the Neutral Point
}

\author{
Ning Li*, Yue Wang ${ }^{\dagger}$, Wanjun Lei ${ }^{*}$, Ruigen Niu* and Zhao'an Wang ${ }^{*}$ \\ ${ }^{* \dagger}$ Department. of Electrical Engineering, Xi'an Jiaotong University, Xi'an, China
}

\begin{abstract}
A novel carrier-based PWM (CBPWM) strategy of a three-level NPC converter is proposed in this paper. The novel strategy can eliminate the low-frequency neutral point (NP) voltage oscillation under the entire modulation index and full power factor. The basic principle of the novel strategy is introduced. The internal modulation wave relationship between the novel CBPWM strategy and traditional SPWM strategy is also studied. All 64 modulation wave solutions of the CBPWM strategy are derived. Furthermore, the proposed CBPWM strategy is compared with traditional SPWM strategy regarding the output phase voltage THD characteristics, DC voltage utilization ratio, and device switching losses. Comparison results show that the proposed strategy does not cause NP voltage oscillation. As a result, no low-frequency harmonics occur on output line-to-line voltage and phase current. The novel strategy also has higher DC voltage utilization ratio (15.47\% higher than that of SPWM strategy), whereas it causes larger device switching losses (4/3 times of SPWM strategy). The effectiveness of the proposed modulation strategy is verified by simulation and experiment results.
\end{abstract}

Key words: Carrier-based PWM strategy, DC voltage utilization ratio, Device switching losses, Low-frequency voltage oscillations, Output phase voltage THD characteristics, Three-level NPC converter

\section{INTRODUCTION}

Three-level NPC converter is one of the most commonly used multilevel converters, of which the main circuit is shown in Fig. 1. Compared with traditional two-level converter, three-level NPC converter has larger output power, smaller output phase voltage THD, less device voltage stress, and lower system EMI. Therefore, the latter is widely applied to high-power system, active power filter, and power system's reactive power compensation [1]-[5].

Neutral point (NP) voltage generally has to be kept at $U_{d c} / 2$ for normal operation of a three-level NPC converter. However, obvious NP voltage oscillations occur in real systems because the NP current $i_{o}$ is not zero in most cases. If the NP voltage is voltage will be unbalanced [6], [7]. The influence will be not controlled, oscillation will occur and the DC capacitor

Manuscript received Jan. 9, 2014; accepted Mar. 12, 2014 Recommended for publication by Associate Editor Yan Xing.

†Corresponding Author: davidwangyue@mail.xjtu.edu.cn Tel: +86-137-7202-3927, Fax: +86-8266-5223, Xi'an Jiaotong University *Dept. of Electronic Engineering, Xi'an Jiaotong University, China

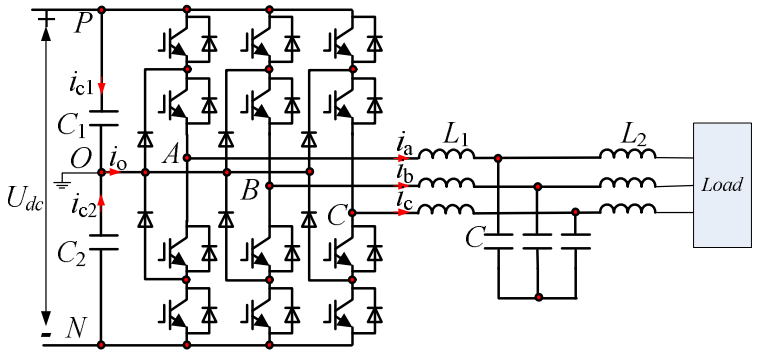

Fig. 1. Scheme of the three-level NPC voltage source. Converter.

transferred to ac side; thus, low-frequency harmonics will appear in the output voltage.

Three methods can be used to control NP voltage oscillations. The first method is achieved by adding an additional hardware NP voltage control circuit in the system [8]. With energy absorbing and feedback from energy storage elements to DC capacitors, the NP voltage is clamped to $U_{\mathrm{dc}} / 2$. However, this method increases the hardware cost and control complexity of the system. Therefore, this method is not commonly used in NPC converters. 
The second method is to add a software NP voltage control scheme [9]-[11]. The control scheme normally modifies the reference signals or output switching states of the modulation strategy to eliminate NP voltage oscillation. In traditional three-level SPWM strategy, zero-sequence component injection scheme is typically used as an NP voltage control scheme. However, considering the fact that the amplitude of the final reference signals should not be greater than that of the carriers, the scheme cannot be used in high-modulation index and low-power factor situations [12]-[14].

The final scheme is to design a modified modulation strategy with a capability of DC voltage balance [15]. In [16] and [17], the low-frequency oscillation in NP voltage was eliminated using virtual vectors in space-vector modulation strategy. Nevertheless, the algorithm was finally implemented using a carrier-based PWM. This algorithm also has to deal with angles and trigonometric functions, which complicates its application. In [18] and [19], a three-level carrier-based PWM (CBPWM) strategy is proposed by dividing the single modulation signal of traditional three-level SPWM strategy into two decoupled signals. However, this strategy only gives a specific solution rather than all solutions to the two modulation waves. Moreover, they did not study the output THD performance, which is an important evaluation index.

The current study investigates a novel CBPWM strategy, which can eliminate low-frequency NP voltage oscillation with any modulation index and power factor. The remaining of this paper is divided into the following sections. Section II studies the modulation wave relationship between the novel strategy and traditional SPWM strategy based on voltage equivalent and NP voltage balance principle. Section III deduces 64 modulation wave solutions of the novel PWM strategy. Section IV analyzes the output phase voltage THD characteristics, DC voltage utilization ratio, and system device switching losses of the novel strategy. Section $\mathrm{V}$ verifies the correctness of the theoretical analysis by simulation and experiment results. Finally, Section VI concludes.

\section{MODULATION WAVE RELATIONSHIP BETWEEN THE NOVEL STRATEGY AND THE SPWM STRATEGY OF A THREE-LEVEL NPC CONVERTER}

The novel strategy is based on the use of two modulation signals for each phase of the converter, as shown in Fig. 2. The two modified modulation signals of each phase satisfy the following expression:

$$
\left\{\begin{array}{l}
U_{x}=U_{x p}+U_{x n}(x=a, b, c) \\
U_{x p} \geq 0, U_{x n} \leq 0 \\
U_{x p \max }=-U_{x n \min }
\end{array},\right.
$$

where $U_{x}$ stands for the modulation wave of traditional

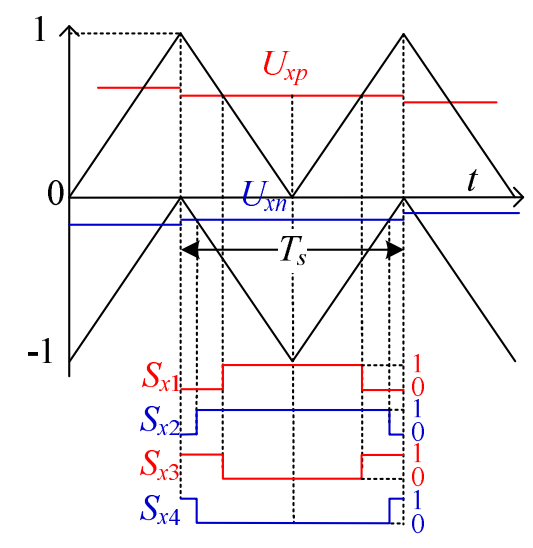

Fig. 2. Diagram of the novel strategy of a three-level NPC.

SPWM strategy; $U_{x p}$ and $U_{x n}$ stand for the two modulation signals of the phase $x(x=a, b, c)$ in the novel strategy. The signals with subscript $p$ will only cross the upper carrier to control the switching devices $S_{x 1}$ and $S_{x 3}$, whereas the signals with subscript $n$ will only cross the lower one to control the switching devices $S_{x 2}$ and $S_{x 4} . U_{x p \max }$ and $U_{x n \min }$ are the maximum and minimum values of the two modulation signals, respectively.

During modulation, the variable $s_{x o}$ defines whether the output state of the phase $x$ is "O," as shown in Fig. 1, $s_{x o} \in\{0,1\}$. When $s_{x o}$ has a unity value, the subsequent phase current $i_{x}$ will flow through NP; otherwise, the phase current $i_{x}$ has no effect on NP current. Therefore, the NP current $i_{o}$ can be expressed as follows:

$$
i_{o}=\sum s_{x o} \cdot i_{x}(x=a, b, c) .
$$

To preserve NP voltage balance, the locally averaged NP current must be zero. Therefore, the averaged NP current, instead of the instantaneous current, must be utilized. The averaged NP current is obtained by using the moving average operator, which is expressed as follows:

$$
\bar{x}(t)=\frac{1}{T_{s}} \int_{t-T_{s}}^{t} x(\tau) d \tau .
$$

Applying this operator to Equation (2), we have

$$
\bar{i}_{o}=\sum d_{x o} \cdot \bar{i}_{x}(x=a, b, c),
$$

where $d_{x o}=\bar{s}_{x o}$ for $x=\{\mathrm{a}, \mathrm{b}, \mathrm{c}\} . \bar{i}_{o}$ and $\bar{i}_{x}$ define the averaged NP and phase currents, respectively. Assuming that the frequency of the carriers in the novel strategy is higher than that of the modulation signals, the duty cycle $d_{x o}$ can be expressed as follows:

$$
d_{x o}=1+U_{x n}-U_{x p}(x=a, b, c) .
$$

The following equation is obtained from Equations (2) to (5):

$$
\bar{i}_{o}=\sum\left(1+U_{x n}-U_{x p}\right) \cdot \bar{i}_{x}(x=a, b, c) .
$$

To remove the low-frequency NP voltage oscillation under any modulation index and power factor, the average NP 
current $\bar{i}_{o}$ should always be zero. Given that the load is star-connected or triangle-connected (Fig. 1), no zero-sequence component exists in the current $i_{x}$. Thus, the sum of the average phase currents $\left(\bar{i}_{x}\right)$ is always zero, that is,

$$
\sum \bar{i}_{x}=0,(x=a, b, c) \text {. }
$$

If

$$
d_{x o}=1+U_{x n}-U_{x p}=k,
$$

then Equation (6) would be

$$
\overline{i_{o}}=\sum\left(1+U_{x n}-U_{x p}\right) \cdot \bar{i}_{x}=k \sum \bar{i}_{x}=0 .
$$

Considering that different circuits have varied load conditions and power factors, Equation (9) is a simple and useful solution of $\overline{i_{o}}=0$. Substituting Equation (9) into Equation (1), the two modulation signals of each phase in the novel CBPWM strategy are obtained as follows:

$$
\left\{\begin{array}{l}
U_{x p}=\frac{U_{x}+1-k}{2} \\
U_{x n}=\frac{U_{x}-1+k}{2}
\end{array} .\right.
$$

In this section, the relationship between the modulation wave $U_{x}$ of traditional SPWM strategy and the modulation waves $U_{x p}$ and $U_{x n}$ of the CBPWM strategy is deduced, as shown in Equation (10). Only one variable $(k)$ is presented in Equation (10). The solution of $k$ will be studied in Section III.

\section{MOdUlation WAVE SOlutions OF THE NOVEL PWM STRATEGY}

In Section II, the expressions of modulation wave of the novel strategy have been deduced. The final problem is to find available solutions to $k$ shown in Equation (10). An infinite number of solutions can generally be found. In the present section, solutions of $k$ will be studied in detail.

In traditional three-level SPWM strategy, each phase has only one modulation signal. If $U_{d c} / 2$ is selected as the base value, the three-phase positive-sequence reference voltages $U_{a 0}, U_{b 0}$, and $U_{c 0}$ in traditional SPWM strategy can be normalized as

$$
\left\{\begin{array}{l}
U_{a 0}=M \cdot \sin \left(\omega_{s} t\right) \\
U_{b 0}=M \cdot \sin \left(\omega_{s} t-2 \pi / 3\right), \\
U_{c 0}=M \cdot \sin \left(\omega_{s} t+2 \pi / 3\right)
\end{array}\right.
$$

where $M$ is the modulation index, and $\omega_{s}$ is the angular frequency of fundamental wave. To utilize DC voltage and improve the system DC voltage utilization ratio, a common method is to inject a zero-sequence voltage $\left(U_{z}\right)$ into the three-phase reference voltages. Hence, the actual reference voltages can be given by

$$
\left\{\begin{array}{l}
U_{a}=U_{a 0}+U_{z} \\
U_{b}=U_{b 0}+U_{z} \\
U_{c}=U_{c 0}+U_{z}
\end{array},\right.
$$

$$
\left\{\begin{array}{l}
U_{x p}=\frac{U_{x 0}+U_{z}+1-k}{2} \\
U_{x n}=\frac{U_{x 0}+U_{z}-1+k}{2}
\end{array} .\right.
$$

In this situation, the modulation waves $U_{x p}$ and $U_{x n}$ of the novel strategy can be expressed as Equation (13). Two variables $\left(k\right.$ and $U_{z}$ ) are presented in the equation. Their appropriate values will make $U_{x p}$ and $U_{x n}$ equal to their extreme values ( 0 or 1 for $U_{x p}, 0$ or -1 for $U_{x n}$ ), which are only the extreme values of the upper and lower carriers, as shown in Fig. 2. Consequently, the output switching state will remain unchanged, which will decrease the system switching losses. In such cases, $k_{x y(j)}$, which defines the solution of $k$ when the value of modulation waves $U_{x y}(x=a, b, c ; y=p, n)$ is $j(j=1,0,-1)$, is expressed as Equation (14).

In Equation (14), two values of $k_{x y(j)}$ can form simultaneous equations to solve the zero-sequence voltage $\left(U_{z}\right)$. As a result, the variable $U_{z}$ yields two solutions. The first solution $\left(U_{z 1}\right)$ is obtained by solving two simultaneous equations of $k_{x y(j)}$ of the same phase, as shown in Equation (15). The second solution $\left[U_{z 2}\right.$ in Equation (15)] is yielded by solving two simultaneous equations of $k_{x y(j)}$ of different phases. Further research shows that $U_{z 1}$ will cause the duty cycle $d_{x o}$ equals to zero, which will make the three-level PWM strategy degenerate into two-level PWM strategy. Therefore, $U_{z 1}$ should be eliminated.

$$
\begin{gathered}
\left\{\begin{array}{l}
k_{x p(1)}=U_{x 0}+U_{z}-1 \\
k_{x p(0)}=U_{x 0}+U_{z}+1 \\
k_{x n(0)}=-U_{x 0}-U_{z}+1 \\
k_{x n(-1)}=-U_{x 0}-U_{z}-1
\end{array}(x=a, b, c)\right. \\
U_{z 1}=\left\{\begin{array}{l}
1-U_{x 0}, k_{x p(1)}=k_{x n(0)} \\
-U_{x 0}, k_{x p(1)}=k_{x n(-1)} \operatorname{ork}_{x p(0)}=k_{x n(0)}(x=a, b, c) \\
-1-U_{x 0}, k_{x p(0)}=k_{x n(-1)}
\end{array}\right. \\
U_{z 2}=\left\{\begin{array}{l}
U_{x 0}+U_{y 0},\left(k_{x p(1)}=k_{y n(0)} \operatorname{ork}_{x n(0)}=k_{y p(1)}\right) \\
-\frac{U_{x 0}+U_{y 0}}{2},\left(\begin{array}{l}
k_{x p(1)}=k_{y n(-1)} \operatorname{ork}_{x p(0)}=k_{y n(0)} \\
\operatorname{ork} k_{x n(0)}=k_{y p(0)} \operatorname{ork}_{x n(-1)}=k_{y p(1)}
\end{array}\right)(x \neq y) \\
-1-\frac{U_{x 0}+U_{y 0}}{2},\left(k_{x p(0)}=k_{y n(-1)} \operatorname{ork} k_{x n(-1)}=k_{y p(0)}\right)
\end{array}\right.
\end{gathered}
$$

The variables $k$ and $U_{z}$ in Equation (13) should realize the modulation waves $U_{x p}$ and $U_{x n}$ with values between their maximum and minimum. Thus, the appropriate $k$ and $U_{z}$ can be obtained with different ranges of $\omega_{s} t$.

$$
\left\{\begin{array}{l}
k= \pm\left(1+\frac{U_{\min }-U_{\max }}{2}\right) \\
U_{z}=-\left(U_{\max }+U_{\min }\right) / 2
\end{array}, \omega_{s} t \in\left[\frac{(2 i-1) \pi}{6}, \frac{(2 i+1) \pi}{6}\right], i=1 \ldots 6\right.
$$

The solutions to $k$ and $U_{z}$ are piecewise functions, as 
shown in Equation (16). In each $\pi / 3$ radian of $\omega_{s} t, k$ has two solutions, whereas $U_{z}$ has only one solution. Totally, $k$ has 64 solutions in each fundamental cycle. Most of these solutions will cause discontinuity of $U_{x p}$ and $U_{x n}$. If $U_{x p}$ and $U_{x n}$ are continuous, they should satisfy Equation (17), where the subscripts "+" and "-" stand for the right and left limits of the signal, respectively. Only two solutions make $U_{x p}$ and $U_{x n}$ satisfy Equation (17), which are shown in Equation (18). Equation (19) and Fig. 3 show the continuous situation of $U_{x p}$ and $U_{x n}(x=a, b, c)$ when the modulation index $M$ equals 1 . In other cases, $U_{x p}$ and $U_{x n}$ are discontinuous. Equation (20) and Fig. 4 show the discontinuous situations of $U_{x p}$ and $U_{x n}$ in the novel strategy $(M=1)$ when $k$ satisfies Equation (21). As shown in Figs. 3 and 4, the modulation waves of the novel strategy remain the same (maximum or minimum) in $1 / 3$ fundamental cycle.

$$
\begin{aligned}
& U_{x y}\left(\frac{(2 i-1) \cdot \pi}{6}\right)_{-}=U_{x y}\left(\frac{(2 i-1) \cdot \pi}{6}\right)_{+},(y=p, n . i=1 \ldots 6) \\
& \left\langle\begin{array}{l}
k_{1}=1+\left(U_{\min }-U_{\max }\right) / 2 \\
k_{2}=\left(U_{\max }-U_{\min }\right) / 2-1
\end{array}, U_{\max }=\max \left(U_{x 0}\right), U_{\min }=\min \left(U_{x 0}\right)\right. \\
& {\left[\begin{array}{l}
U_{x p} \\
U_{x n}
\end{array}\right]=\left\{\begin{array}{l}
{\left[\begin{array}{l}
\left(U_{x 0}-U_{\min }\right) / 2 \\
\left(U_{x 0}-U_{\max }\right) / 2
\end{array}\right], k=k_{1}} \\
{\left[\begin{array}{l}
\left(2+U_{x 0}-U_{\max }\right) / 2 \\
\left(U_{x 0}-U_{\min }-2\right) / 2
\end{array}\right], k=k_{2}}
\end{array}, \omega t \in\left[\frac{(2 i-1) \pi}{6}, \frac{(2 i+1) \pi}{6}\right]\right.} \\
& {\left[\begin{array}{l}
U_{x p} \\
U_{x n}
\end{array}\right]=\left\{\begin{array}{l}
{\left[\begin{array}{l}
\frac{U_{x 0}-U_{\min }}{2} \\
\frac{U_{x 0}-U_{\max }}{2}
\end{array}\right], \omega_{s} t \in\left[\frac{i \pi}{3}-\frac{\pi}{2}, \frac{i \pi}{3}-\frac{\pi}{6}\right](i=1,3,5)} \\
{\left[\begin{array}{l}
\frac{2+U_{x 0}-U_{\max }}{2} \\
\frac{U_{x 0}-U_{\min }-2}{2}
\end{array}\right], \omega_{s} t \in\left[\frac{i \pi}{3}-\frac{\pi}{2}, \frac{i \pi}{3}-\frac{\pi}{6}\right](i=2,4,6)}
\end{array}\left(k=k_{3}\right)\right.} \\
& {\left[\begin{array}{l}
U_{x p} \\
U_{x n}
\end{array}\right]=\left\{\begin{array}{l}
{\left[\begin{array}{l}
\frac{2+U_{x 0}-U_{\max }}{2} \\
\frac{U_{x 0}-U_{\min }-2}{2}
\end{array}\right], \omega_{s} t \in\left[\frac{i \pi}{3}-\frac{\pi}{2}, \frac{i \pi}{3}-\frac{\pi}{6}\right](i=1,3,5)} \\
{\left[\begin{array}{l}
\frac{U_{x 0}-U_{\min }}{2} \\
\frac{U_{x 0}-U_{\max }}{2}
\end{array}\right], \omega_{s} t \in\left[\frac{i \pi}{3}-\frac{\pi}{2}, \frac{i \pi}{3}-\frac{\pi}{6}\right](i=2,4,6)}
\end{array} \quad\left(k=k_{4}\right)\right.}
\end{aligned}
$$$$
k_{3}=\left\{\begin{array}{l}
1+\frac{\left(U_{\min }-U_{\max }\right)}{2}, \omega_{s} t \in\left[\frac{i \pi}{3}-\frac{\pi}{2}, \frac{i \pi}{3}-\frac{\pi}{6}\right](i=1,3,5) \\
\frac{\left(U_{\max }-U_{\min }\right)}{2}-1, \omega_{s} t \in\left[\frac{i \pi}{3}-\frac{\pi}{2}, \frac{i \pi}{3}-\frac{\pi}{6}\right](i=2,4,6)
\end{array}\right.
$$$$
k_{4}=\left\{\begin{array}{l}
\frac{\left(U_{\max }-U_{\min }\right)}{2}-1, \omega_{s} t \in\left[\frac{i \pi}{3}-\frac{\pi}{2}, \frac{i \pi}{3}-\frac{\pi}{6}\right](i=1,3,5) \\
1+\frac{\left(U_{\min }-U_{\max }\right)}{2}, \omega_{s} t \in\left[\frac{i \pi}{3}-\frac{\pi}{2}, \frac{i \pi}{3}-\frac{\pi}{6}\right](i=2,4,6)
\end{array}\right.
$$

In this part, the modulation wave solutions of the novel

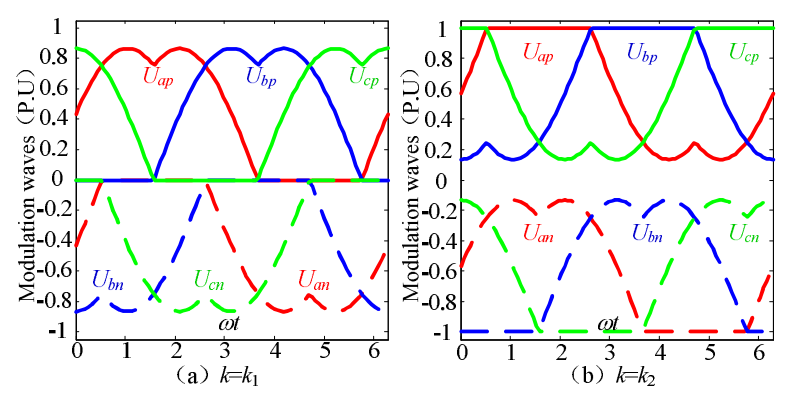

Fig. 3. Continuous situations of $U_{x p}$ and $U_{x n}$ of the CBPWM strategy $(M=1)$.

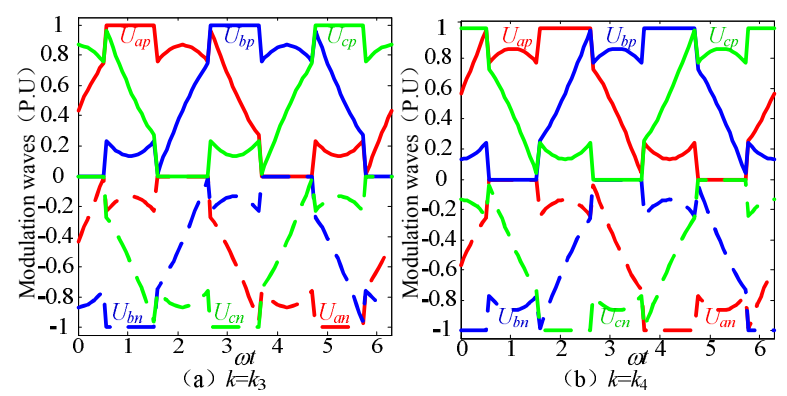

Fig. 4. Discontinuous situations of $U_{x p}$ and $U_{x n}$ of the CBPWM strategy $(M=1)$.

CBPWM strategy are discussed. In general, 64 modulation wave solutions are obtained, among which 2 are continuous and the other 62 are discontinuous. The system line-to-line voltage applying each of the 64 modulation wave solutions is the same as that of the traditional SPWM strategy because $k$ and $U_{z}$ are eliminated in the line-to-line voltage expression.

\section{Characteristic ANALYSIS OF THE NOVEL STRATEGY}

In Section III, the modulation wave solutions of the novel PWM strategy have been deduced. To give a comprehensive evaluation of the novel strategy, the characteristics of DC voltage utilization ratio, device switching losses, and output phase voltage THD characteristics are analyzed in the current section.

\section{A. DC Voltage Utilization Ratio and Device Switching Losses of the Novel PWM Strategy}

DC voltage utilization ratio is an important evaluation index of PWM strategy. This ratio equals to the ratio of fundamental amplitude of output line-to-line voltage and total DC voltage, that is,

$$
\eta=\frac{U_{a b 1}}{U_{d c}},
$$

where $U_{a b 1}$ is the fundamental amplitude of the output line-to-line voltage.

According to Equation (16), the expression of the zero-sequence voltage injected into the phase voltage is the same as the modulation wave difference between traditional 
three-level SVPWM strategy and SPWM strategy. As a result, the DC utilization ratio of the novel strategy (all of the 64 modulation wave solutions) is the same as that of the SVPWM strategy $(15.47 \%$ higher than that of the three-level SPWM strategy).

System device losses are another important evaluation standard for modulation strategy. The preceding analysis indicates that the three-phase modulation waves of the proposed CBPWM strategy (all of the 64 modulation wave solutions) remain the extreme values in $1 / 3$ fundamental cycle. As a result, the output switching states of each phase remain unchanged in 1/3 fundamental cycle. By contrast, when the three-level SPWM strategy is used, the output switching states of each phase remain the same in $1 / 2$ fundamental cycle. Therefore, the total switching losses of the novel CBPWM strategy are 4/3 times of the traditional three-level SPWM strategy assuming that the system switching losses are proportional to the switching frequency.

\section{B. Phase Voltage THD Characteristics of the Novel PWM Strategy}

Output phase voltage (the earth point is the NP "O" in Fig. 1) THD characteristic is another important evaluation standard of modulation strategy. In this study, double-Fourier analysis is used to analyze the output phase voltage THD characteristic of the novel PWM strategy. The expression and coefficients of double-Fourier analysis are shown in Equations (23) and (24), respectively. In these equations, $\omega_{s}$ stands for the modulation wave angular frequency, and $\omega_{c}$ stands for the carrier-wave angular frequency. $A_{00}$ is the coefficient of the zero-sequence components; $A_{0 n}$ and $B_{0 n}, A_{m 0}$ and $B_{m 0}$, and $C_{m n}$ are the coefficients of baseband, carrier, and sideband harmonics, respectively.

$$
\begin{gathered}
F\left(\omega_{c} t, \omega_{s} t\right)=\frac{A_{00}}{2}+\sum_{n=1}^{\infty}\left\{A_{0 n} \cos \left(n \omega_{s} t\right)+B_{0 n} \sin \left(n \omega_{s} t\right)\right\} \\
+\sum_{m=1}^{\infty}\left\{A_{m 0} \cos \left(m \omega_{c} t\right)+B_{m 0} \sin \left(m \omega_{c} t\right)\right\} \\
+\sum_{m=1}^{\infty} \sum_{n= \pm 1}^{ \pm \infty}\left\{A_{m n} \cos \left(m \omega_{c} t+n \omega_{s} t\right)+B_{m n} \sin \left(m \omega_{c} t+n \omega_{s} t\right)\right\} \\
C_{m n}=A_{m n}+j B_{m n}=\frac{1}{2 \pi^{2}} \int_{-\pi}^{\pi} \int_{-\pi}^{\pi} F\left(\omega_{c} t, \omega_{s} t\right) e^{j\left(m \omega_{c} t+n \omega_{s} t\right)} d \omega_{c} t d \omega_{s} t
\end{gathered}
$$

During coefficient solving, the trigonometric-function integral that contains triangle variables [such as $\cos (\xi \cos \theta)$ and $\sin (\xi \cos \theta)$ ] must frequently be solved. In these situations, Jacobi-Anger expansions, which are shown in Equation (25), can be used to expand the triangle variables into Bessel series forms [20].

$$
\left\{\begin{array}{l}
\cos (\xi \cos \theta)=J_{0}(\xi)+2 \sum_{l=1}^{\infty} \cos (l \pi) J_{2 l}(\xi) \cos (2 l \theta) \\
\sin (\xi \cos \theta)=2 \sum_{l=0}^{\infty} \cos (l \pi) J_{2 l+1}(\xi) \cos [(2 l+1) \theta]
\end{array}\right.
$$
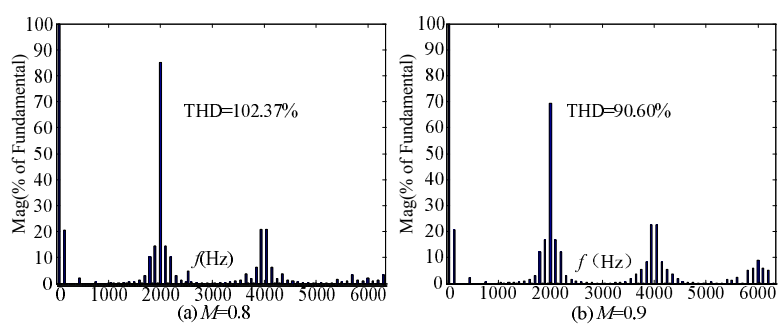

Fig. 5. Diagram of phase voltage THD characteristics of the novel strategy.

$$
\left\{\begin{array}{l}
B_{01}=\frac{M U_{d c}}{2} \\
A_{0 n}=\frac{\sqrt{3} M U_{d c}\left[1-(-1)^{n}\right]}{4 \pi\left(n^{2}-1\right)}\left\{\left[1+(-1)^{n}\right] \cos \left(\frac{n \pi}{6}\right)-\cos \left(\frac{n \pi}{2}\right)\right\} \\
B_{0 n}=\frac{\sqrt{3} M U_{d c}\left[1-(-1)^{n}\right]}{4 \pi\left(n^{2}-1\right)}\left\{\left[1+(-1)^{n+1}\right] \sin \left(\frac{n \pi}{6}\right)-\sin \left(\frac{n \pi}{2}\right)\right\} \\
A_{m 0}=\frac{\left[1+(-1)^{m+1}\right] U_{d c}}{m \pi^{2}} \sum_{l=0}^{\infty} \frac{\cos (l \pi)}{(2 l+1)} J_{2 l+1}\left(\frac{\sqrt{3} m M \pi}{2}\right) \cdot Y \\
Y=2 \sin \left[\frac{(2 l+1) \pi}{3}\right]^{2}+1+\cos \left[\frac{(2 l+1) \pi}{3}\right]
\end{array}\right.
$$

$$
C_{m n}=\left\{\begin{array}{l}
A \cdot \sum_{l=0}^{\infty} \frac{\cos (l \pi) J_{2 l+1}\left(\frac{\sqrt{3} m M \pi}{2}\right)}{(2 l+1)^{2}-n^{2}} \cdot X,(n \neq 2 l+1) \\
\frac{2\left[1+(-1)^{m}\right] U_{d c}}{3 m \pi} \sum_{l=0}^{\infty} \cos (l \pi) \cdot Y,(n=2 l+1) \\
A=\frac{\left[1+(-1)^{m+n+1}\right] U_{d c}}{m \pi^{2}} \\
X=(2 l+1)\left[1+(-1)^{n}\right] \cos \left(\frac{n \pi}{6}\right) \\
\quad+j(2 l+1)\left[(-1)^{n}-1\right] \sin \left(\frac{n \pi}{6}\right) \\
+e^{j \frac{n \pi}{2}}\left[2(2 l+1) \cdot \cos \left(\frac{\pi \cdot(2 l+1)}{3}\right)\right] \\
Y=J_{2 l+1}\left(\frac{\sqrt{3} m M \pi}{2}\right) \cos \left(\frac{\pi(2 l+1)}{6}\right)
\end{array}\right.
$$

Two modulation waves of each phase exist in the novel strategy. As a result, the double-Fourier analysis results of the two modulation waves should be added to obtain the phase voltage THD. Based on Equations (13) and (19), all of the 64 modulation wave solutions of the novel strategy have the same THD performance. The coefficients of harmonic components are shown in Equations (26) and (27).

Fig. 5 shows the output phase voltage THD performance of the novel PWM strategy when the modulation index $(M)$ equals to 0.8 and 0.9 . According to the output phase voltage waveform expressions (26) and (27) and Fig. 7, for a given value of $M$, the following findings are obtained:

1) Compared with the output phase voltage harmonic components of the traditional three-level SPWM strategy, 
the output phase voltage of the novel strategy also contains odd carrier harmonics, even sideband harmonics ( $n$ is even) around the odd carrier multiples ( $m$ is odd), and odd sideband harmonics ( $n$ is odd) around the even carrier multiples ( $m$ is even). The angular frequencies of the main harmonics are $\omega_{c}, \omega_{c} \pm 2 \omega_{s}$, and $2 \omega_{c} \pm \omega_{s}$. These components will be greatly reduced by output filter because their frequencies are higher than the fundamental frequency. The only difference is that $6 i-3(i=1,2,3 \ldots)$ multiples of baseband harmonics are remain in the output phase voltage because of the existence of zero-sequence component in the three-phase reference voltage. These low-frequency harmonics will not appear in the line-to-line voltage and phase current because the load is star-connected or triangle-connected.

2) With the increase of $M$, the output phase voltage THD of the novel strategy gradually decreases. This characteristic is consistent with traditional SPWM strategy.

3) The THD performances of the novel CBPWM strategy and traditional SPWM strategy are difficult to compare because the NP voltage oscillation caused by the SPWM strategy will influence its THD characteristic.

In this part, the DC voltage utilization ratio, device switching losses, and output phase voltage THD characteristics of the novel strategy are studied. Compared with traditional SPWM strategy, the novel PWM strategy has higher DC voltage utilization ratio but larger device switching losses. In terms of output phase voltage THD, the novel strategy does not cause NP voltage oscillations. The output phase voltage THD of the novel strategy is only influenced by the system modulation index $(M)$. On the contrary, the output phase voltage THD of the SPWM strategy is influenced by the system modulation index $(M)$ and NP voltage oscillations. Moreover, the output line-to-line voltage and phase current will not contain low-frequency harmonics if the novel PWM strategy is used.

\section{SIMULATION AND EXPERIMENT VERIFICATIONS}

The effect of the proposed novel PWM strategy is verified by simulation and experiment. The diagram of the simulation and experimental power circuits is shown in Fig. 1. The values of the dc-link voltage and capacitors are $U_{d c}=400 \mathrm{~V}$ and $C_{1}=C_{2}=1000 \mu \mathrm{F}$, respectively. The load is connected to the three-level NPC VSC through an LCL filter $\left(L_{1}=L_{2}=3 \mathrm{mH}, \quad C=17 \mathrm{uF}\right)$ with star connection. The proposed novel CBPWM strategy is implemented in a fully digital system using a TMS320F2812 DSP. The switching frequency is $2 \mathrm{kHz}$.

Figs. 6 and 7 show the simulation results of output phase voltage $\left(U_{a o}\right)$, line voltage $\left(U_{b c}\right)$, DC capacitor voltages $\left(U_{c 1,2}\right)$, and load current $\left(i_{a, b, c}\right)$ of the standard SPWM strategy and the novel PWM strategy proposed in this paper. The modulation index of the system is 0.8 . Three-phase resistive load $(R=15 \Omega$, star-connected $)$ and inductive load

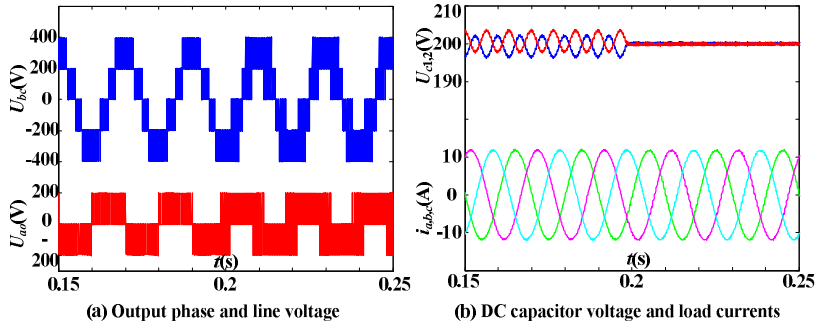

Fig. 6. Simulation results of the standard SPWM and novel PWM strategies (resistor load, $M=0.8, k=k_{1}$ ).
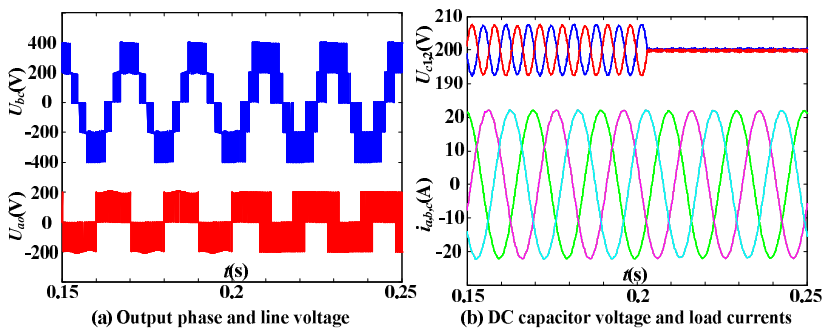

Fig. 7. Simulation results of the standard SPWM and novel PWM strategies (inductive load, $M=0.8, k=k_{1}$ ).

( $L=20 \mathrm{mH}$, star-connected) are used in Figs. 6 and 7, respectively. The modulation strategy changes from the SPWM strategy to the novel PWM strategy $\left(k=k_{1}\right)$ when $t=0.2 \mathrm{~s}$. The simulation results indicate that the novel CBPWM strategy can completely eliminate the low-frequency NP voltage oscillation compared with traditional SPMW strategy.

Fig. 8 shows the contrastive experiment results of the standard SPWM and novel PWM strategies in different modulation indices $(M=0.8$ and 0.9$)$ with three-phase resistive load ( $R=15 \Omega$, star-connected). Figs. 8(a) and(b) show the results obtained by applying the standard SPWM strategy. The variables shown are a line-to-line voltage $U_{c b}$, the output phase voltage $U_{a o}$, the voltage on the DC capacitor $U_{c 1}$, and the output load current $i_{c}$. Figs. 8(c) to(j) show the same results when the proposed novel PWM strategy is applied. Table I shows the main harmonics of the experimental DC capacitor voltage results when traditional SPWM strategy and the novel PWM strategy are used. Fig. 8 and Table I indicate that significant low-fundamental frequency (the fundamental frequency is $50 \mathrm{~Hz}$ in this study) voltage oscillations occur on the DC capacitor when traditional SPWM strategy is used. Moreover, the DC components of the two DC capacitor voltages are not equal. When the novel PWM strategy is used, the voltage on the DC capacitor does not contain any low-frequency oscillation but only high-frequency ripples, which are related to the switching frequency. The unbalance of DC capacitor voltage is also greatly reduced. However, the switching frequencies of switching devices increase when the novel PWM strategy is applied compared with those when traditional SPWM strategy is used. The reason is that the two modulation waves 


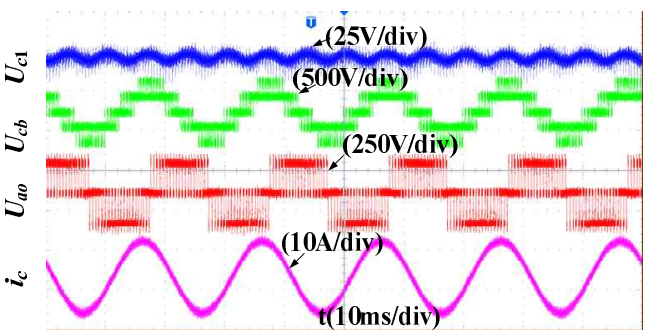

(a) $M=0.8$, SPWM strategy

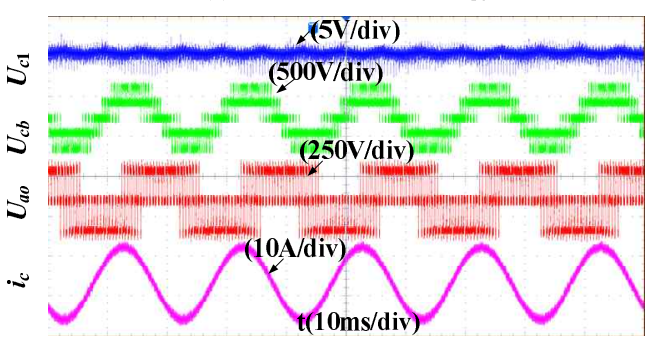

(c)M=0.8, the novel PWM strategy $\left(k=k_{1}\right)$

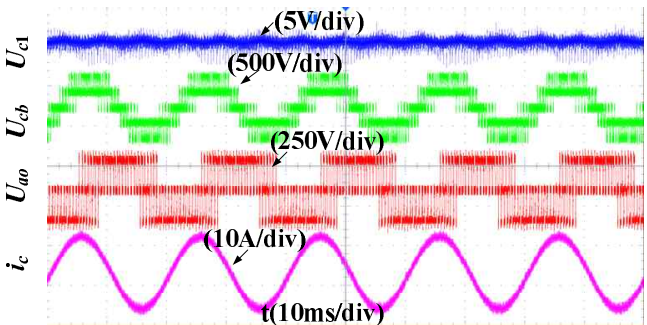

(e) $M=0.8$, the novel PWM strategy $\left(k=k_{2}\right)$

(5V/div)

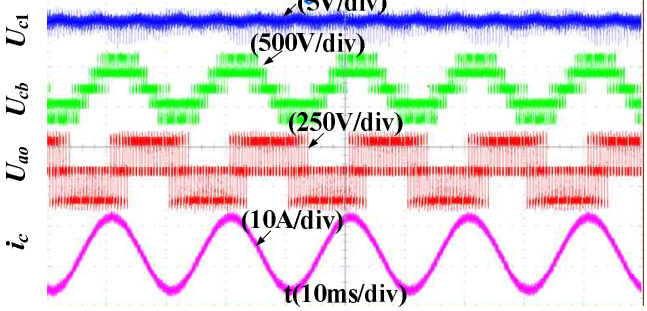

(g) $M=0.8$, the novel PWM strategy $\left(k=k_{3}\right)$

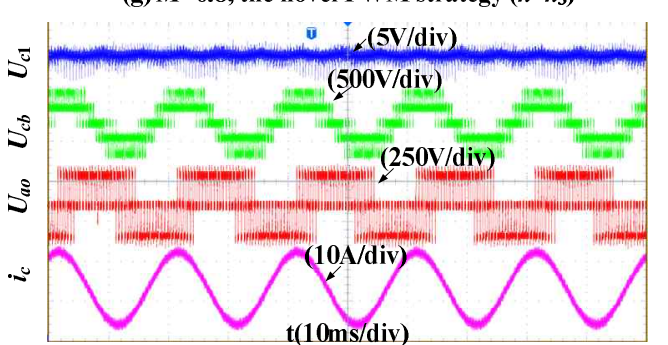

(i) $M=0.8$, the novel PWM strategy $\left(k=k_{4}\right)$

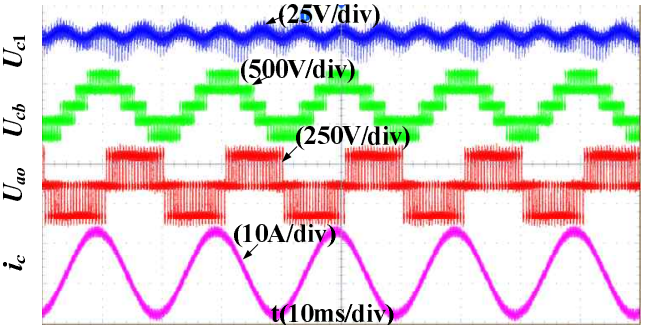

(b) $M=0.9$, SPWM strategy

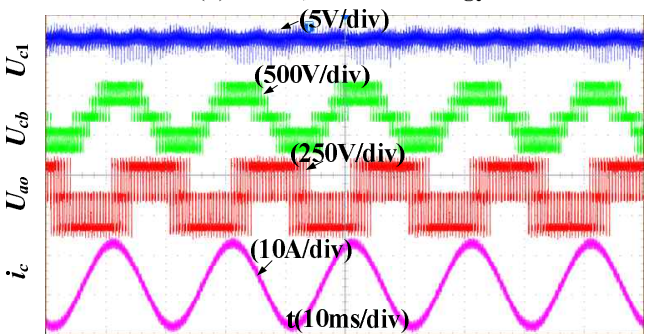

(d) $M=0.9$, the novel PWM strategy $\left(k=k_{1}\right)$

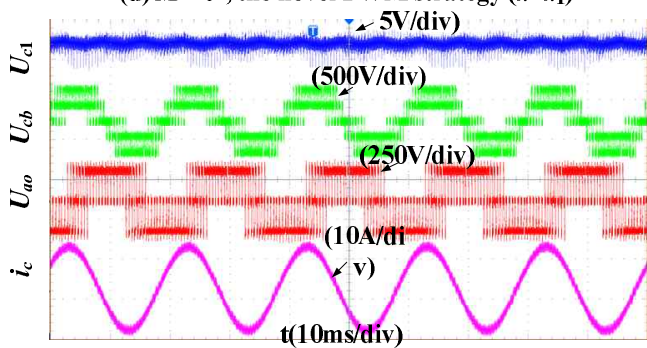

(f) $M=0.9$, the novel PWM strategy $\left(k=k_{2}\right)$

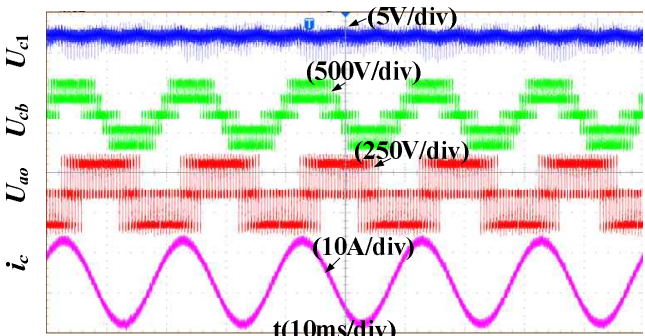

(h) $M=0.9$, the novel PWM strategy $\left(k=k_{3}\right)$

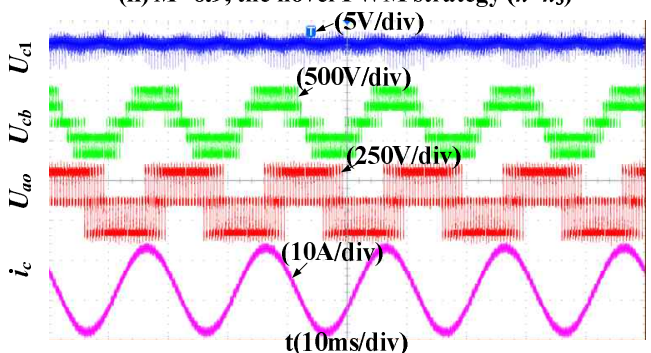

(j) $M=0.9$, the novel PWM strategy $\left(k=k_{4}\right)$

Fig. 8. Experimental results of the standard SPWM and novel PWM strategies.

in the novel PWM strategies are not clamped to their extreme values in half of the fundamental cycle.

Table II shows the THD characteristic comparison of the results of the experiment applying the novel PWM strategy. Tables I and II indicate that the four modulation wave solutions with the same modulation index $(M)$ have the same THD characteristics, which is consistent with the preceding analysis.

Three-phase inductive load (20 $\mathrm{mH}$, star-connected) is used to confirm the DC voltage control effect of the novel PWM strategy under high-modulation index and low-power factor, in which the low-frequency NP voltage oscillations cannot be eliminated by traditional SPWM strategy with a zero-sequence component injection scheme [13]-[15]. Fig. 9(a) shows the 
TABLE I

Main HaRmonic Components of the Experimental DC CAPACITOR VOLTAGES USING THE NOVEL PWM STRATEGY AND SPWM STRATEGY

\begin{tabular}{|c|c|c|c|c|}
\hline \multicolumn{2}{|c|}{ Modulation index and wave } & $\begin{array}{c}U_{\mathrm{cl}}(\mathrm{DC} \\
\text { value }) / \mathrm{V}\end{array}$ & $\begin{array}{c}U_{\mathrm{cl} 1}(3 \mathrm{rd} \\
\text { harmonic }) / \mathrm{V}\end{array}$ & $\begin{array}{c}U_{\mathrm{c} 2}(\mathrm{DC} \\
\text { value }) / \mathrm{V}\end{array}$ \\
\hline \multirow{5}{*}{0.8} & SPWM & 208.4 & 2.07 & 191.6 \\
\hline & Novel PWM $\left(k=k_{1}\right)$ & 197.6 & 0.058 & 202.4 \\
\hline & Novel $\operatorname{PWM}\left(k=k_{2}\right)$ & 198.1 & 0.03 & 201.9 \\
\hline & Novel $\operatorname{PWM}\left(k=k_{3}\right)$ & 198.6 & 0.054 & 201.4 \\
\hline & Novel PWM $\left(k=k_{4}\right)$ & 199 & 0.04 & 201 \\
\hline \multirow{5}{*}{0.9} & SPWM & 192.9 & 2.57 & 207.1 \\
\hline & Novel PWM $\left(k=k_{1}\right)$ & 199 & 0.04 & 201 \\
\hline & Novel PWM $\left(k=k_{2}\right)$ & 198.7 & 0.055 & 201.3 \\
\hline & Novel $\operatorname{PWM}\left(k=k_{3}\right)$ & 198.9 & 0.03 & 201.1 \\
\hline & Novel $\operatorname{PWM}\left(k=k_{4}\right)$ & 199.9 & 0.03 & 200.1 \\
\hline
\end{tabular}

TABLE II

THD CHARACTERISTIC COMPARISON OF THE RESULTS OF THE EXPERIMENT APPLYING THE NOVEL PWM STRATEGY

\begin{tabular}{|c|c|c|c|c|}
\hline \multicolumn{2}{|c|}{ Novel PWM strategy } & $\begin{array}{c}\text { THD of } \\
U_{c o}(\%)\end{array}$ & $\begin{array}{c}\text { THD of } \\
U_{b a}(\%)\end{array}$ & $\begin{array}{c}\text { THD of } \\
i_{a}(\%)\end{array}$ \\
\hline \multirow{4}{*}{$M=0.8$} & $k=k_{1}$ & 99.6 & 48.84 & 2.81 \\
\cline { 2 - 5 } & $k=k_{2}$ & 100.21 & 47.03 & 2.84 \\
\cline { 2 - 5 } & $k=k_{3}$ & 99.16 & 48.58 & 2.75 \\
\cline { 2 - 5 } & $k=k_{4}$ & 98.69 & 49.07 & 2.68 \\
\hline \multirow{4}{*}{$M=0.9$} & $k=k_{1}$ & 89.42 & 49.73 & 2.57 \\
\cline { 2 - 5 } & $k=k_{2}$ & 89.33 & 49.79 & 2.61 \\
\cline { 2 - 5 } & $k=k_{3}$ & 89.91 & 49.73 & 2.54 \\
\cline { 2 - 5 } & $k=k_{4}$ & 89.08 & 49.86 & 2.6 \\
\hline
\end{tabular}

experiment results of the traditional SPWM strategy, and those of the SPWM strategy with zero-sequence component injection are shown in Fig. 9(b). Figs. 9(c) and 9(d) show the experimental results when the novel PWM strategy is used. All of the four experimental results are obtained under the same system condition $\left(U_{d c}=200 \mathrm{~V}, M=0.8\right.$, power factor angle $\left.\varphi=90^{\circ}\right)$.

The experimental results indicate that when the system modulation index $(M)$ is high and the output power factor is low, traditional SPWM strategy with zero-sequence component injection cannot eliminate the low-frequency oscillation existing in the DC capacitor voltage. The reason is that in such a case $(M=0.8, \cos \varphi=0)$, the maximum of the phase reference signal $U_{x}(\mathrm{x}=\mathrm{a}, \mathrm{b}, \mathrm{c})$, which is the sum of positive-sequence reference signal $U_{x 0}$ and the zero-sequence component $U_{z}$, is larger than that of the carrier [13]-[15]. By contrast, the novel PWM strategy proposed in this paper can solve the problem very well.

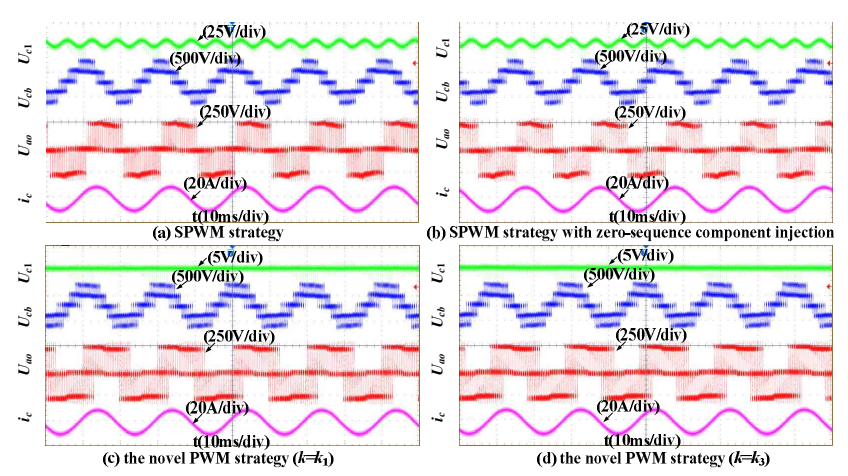

Fig. 9. Comparison of SPWM and the novel PWM strategy under high-modulation index and low-power factor $(M=0.8, \cos \varphi=0)$.

\section{CONCLUSIONS}

This paper presents a novel PWM strategy that can eliminate low-frequency NP voltage oscillations of a three-level NPC converter under any system modulation index and output power factor. The modulation wave relationship between the novel PWM strategy and traditional SPWM strategy is first investigated. The operation principle and modulation wave solving process of the proposed PWM strategy is then analyzed in details. The proposed PWM strategy are also compared with traditional SPWM strategy in terms of output phase voltage harmonic characteristic, device switching losses, and DC voltage utilization rate. Finally, numerical simulation and experiment results are given to verify the theoretical analysis.

With the proposed PWM strategy solutions, which can be directly implemented in a simple microprocessor and does not cause low-frequency voltage oscillation in the NP, three-level NPC VSC is a promising and competitive topology for wide range power conversion in renewable energy applications and many other low-power applications. The proposed PWM strategies can also be extended to the application of three-level NPC SVG, three-level NPC APF, and three-level ANPC VSI [21]-[23].

\section{ACKNOWLEDGMENT}

This work was supported in part by the State Key Laboratory of Electrical Insulation and Power Equipment (China) and by the National "863" Program of China under Project 2012AA050206.

\section{REFERENCES}

[1] L. G. Franquelo, J. Rodríguez, J. I. León, S. Kouro, R. Portillo, and M. M. Prats, "The age of multilevel converters arrives," IEEE Ind. Electron. Mag., Vol. 2, No. 2, pp. 28-39, Jun. 2008.

[2] J. Rodríguez, L. G. Franquelo, S. Kouro, J. I. León, R. C. Portillo, M. M. Prats, and M. A. Perez, "Multilevel 
converters: An enabling technology for high-power applications," in Proc. IEEE , Vol. 97, No. 11, pp. 1786-1817, Nov. 2009.

[3] S. Kouro, M. Malinowski, K. Gopakumar, J. Pou, L. G. Franquelo, B. Wu, J. Rodríguez, M. A. Pérez, and J. I. León, "Recent advances and industrial applications of multilevel converters," IEEE Trans. Ind. Electron., Vol. 57, No. 8, pp. 2553-2580, Aug. 2010.

[4] H. Abu-Rub, J. Holtz, J. Rodríguez, and G. Baoming, "Medium-voltage multilevel converters-State of the art, challenges, and requirements in industrial applications," IEEE Trans. Ind. Electron. , Vol. 57, No. 8,pp. 2581-2596, Aug. 2010

[5] A. Nabae, I. Takahashi, and H. Akagi, "A new neutral-point-clamped PWM inverter," IEEE Trans. Ind. Appl., Vol. A-17, No. 5, pp. 518-523,Sep./Oct. 1981.

[6] N. Celanovic and D. Boroyevich, "A comprehensive study of neutral-point voltage balancing problem in three-level neutral-point-clamped voltage source PWM inverters," IEEE Trans. Power Electron., Vol. 15, No. 2,pp. 242-249, Mar. 2000.

[7] J. Pou, R. Pindado, D. Boroyevich, and P. Rodríguez, "Evaluation of the low-frequency neutral-point voltage oscillations in the three-level inverter," IEEE Trans. Ind. Electron. , Vol. 52, No. 6, pp. 1582-1588, Dec. 2005.

[8] Salvador Ceballos, J. Pou, J. Zaragoza, Eider Robles, José Luis Villate, and José Luis Martín, "Fault-tolerant neutral-point-clamped converter solutions based on including a fourth resonant leg," IEEE Trans. Ind. Electron. , Vol. 58, No. 6, pp. 2293-2303, Dec. 2011.

[9] J. Pou, J. Zaragoza, S. Ceballos, M. Saeedifard, and D. Boroyevich," A carrier-based PWM strategy with zero-sequence voltage injection for a three-level neutral-point-clamped converter," IEEE Trans. Power Electron., Vol. 27, No. 2,pp. 642-651, Feb. 2012.

[10] Y. He, J. Liu, J. Tang, Z. Wang, and Y. Zou, "Theoretical analysis and control of DC neutral-point voltage balance of three-level inverters in active power filters," Journal of Power Electronics, Vol. 12, No. 2, pp.344-356, Mar. 2012

[11] U.-M. Choi and K.-B. Lee, "Neutral-point voltage balancing method for three-level inverter systems with a time-offset estimation scheme," Journal of Power Electronics, Vol. 13, No. 2, 243-249, Mar. 2013

[12] S. Qiang, L. Wenhua, Y. Qingguang, X. Xiaorong, and W. Zhonghong, "A neutral-point potential balancing algorithm for three-level NPC in-verters using analytically injected zero-sequence voltage," in Proc. IEEE Appl. Power. Electron. Conf., pp. 228-233, 2003.

[13] C. Wang and Y. Li, "Analysis and calculation of zero-sequence voltage considering neutral-point potential balancing in three-level npc converters," IEEE Trans. Ind. Electron., Vol. 57, No. 7,pp. 2262-2271, Jul. 2010.

[14] J. Zaragoza, J. Pou, S. Ceballos, E. Robles, C. Jaen, and M. Corbalan, "Voltage-balance compensator for carrier-based modulation in the neutral point-clamped converter," IEEE Trans. Ind. Electron., Vol. 56, No. 2,pp. 305-314, Feb. 2009.

[15] R. M. Tallam, R. Naik, and T. A. Nondahl, "A carrier-based PWM scheme for neutral-point voltage balancing in three-level inverters," IEEE Trans. Ind. Appl., Vol. 41, No. 6, pp. 1734-1743, Dec. 2005.

[16] S. Busquets-Monge, J. Bordonau, D. Boroyevich, and S. Somavilla, "The nearest three virtual space vector PWM-A modulation for the comprehensive neutral-point balancing in the three-level NPC inverter," IEEE Power
Electron. Lett., Vol. 2, No. 1, pp. 11-15, Mar. 2004.

[17] S. B. Monge, S. Somavilla, J. Bordonau, and D. Boroyevich, "Capacitor voltage balance for the Neutral-Point-Clamped converter using the virtual space vector concept with optimized spectral performance," IEEE Trans. Power Electron., Vol. 22, No. 4, pp. 1128-1135, Jul. 2007.

[18] J. Pou, J. Zaragoza, P. Rodríguez, S. Ceballos, V. Sala, R. Burgos, and D. Boroyevich, "Fast-processing modulation strategy for the neutral-point-clamped converter with total elimination of the low-frequency volt-age oscillations in the neutral point," IEEE Trans. Ind. Electron., Vol. 54, No. 4, pp. 2288-2294, Aug. 2007.

[19] J. Zaragoza, J. Pou, S. Ceballos, E. Robles, C. Jaen, and M. Corbalan, "Voltage-balance compensator for carrier-based modulation in the neutral-point-clamped converter," IEEE Trans. Ind. Electron., Vol. 56, No. 2,pp. 305-314, Feb. 2009.

[20] D. G. Holmes and A. L. Thomas, Pulse width modulation for power converters: principles and practice, Hoboken, NJ: Wiley-IEEE Press, pp. 623-633, 2003.

[21] D. Andler, R. Alvarez, S. Bernet, and J.Rodriguez, "Experimental investigation of the commutations of a 3L-ANPC phase leg using 4.5-kV-5.5-kA IGCTs," IEEE Trans. Ind. Electron., Vol.60, No.11, pp. 4820-4830, Nov. 2013.

[22] J. Li, P. Fazio, A. Q. Huang, Z. Liang, and S. Bhattacharya, "Analysis and design of active NPC (ANPC) inverters for fault-tolerant operation of high-power electrical drives," IEEE Trans. Power Electron., Vol. 27, No. 2,pp. 519-533, Feb. 2012.

[23] O. S. Senturk, L. Helle, S. Munk-Nielsen, P. Rodriguez, and R. Teodorescu, "Power capability investigation based on electrothermal models of press-pack IGBT three-level NPC and ANPC VSCs for multimegawatt wind turbines," IEEE Trans. Power Electron., Vol. 27, No. 7, pp. 3195-3206, Jul. 2012.

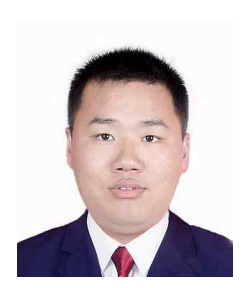

Ning Li (S'09) received his B.S. and M.S. degrees in Electrical Engineering from Xi'an Jiaotong University, Xi'an, China in 2006 and 2009 , respectively. He is currently working toward his Ph.D. degree at the same university. His current research interests include multilevel converter, wind power generation, and power electronics.

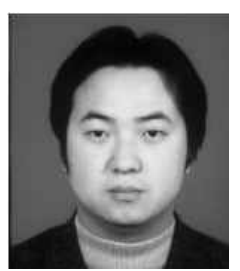

Yue Wang (M'05) received his B.S. degree from Xi'an Jiaotong University, Xi'an, China in 1994; M.S. degree from Beijing Jiaotong University, Beijing, China in 2000; $\mathrm{Ph} . \mathrm{D}$. degree from Xi'an Jiaotong University in 2004. He is currently an Associate Professor at Xi'an Jiaotong University. His current research interests include active power filters, wind power generation, motor drives, multilevel converters, and flexible ac power transmission. 


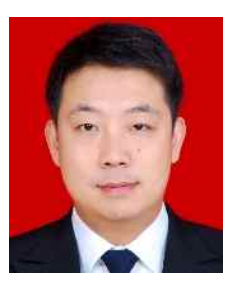

Wanjun Lei received his B.Sc., M.Sc., and Ph.D. degrees in Electrical Engineering from $\mathrm{Xi}$ 'an Jiaotong University, China. He is an assistant professor in the Department of Industry Automation, Power Electronics, and Renewable Energy Research Center at this university. He is a member of China Power Supply Society and IEEE. His current research focuses on power electronics inverter and power quality control technique.

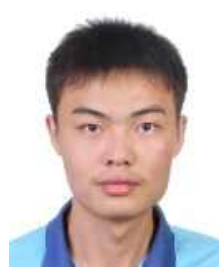

Ruigen Niu received his B.S. degree from Xi'an Jiaotong University, Xi'an, China in 2008, where he is currently a Researcher at the School of Electrical Engineering. His current research interests include power quality of wind power generation.

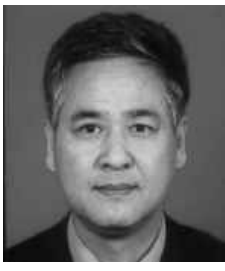

Zhao'an Wang (SM'98) received his B.S. and M.S. degrees from Xi'an Jiaotong University, Xi'an, China in 1970 and 1982, respectively. He also received his Ph.D. degree from Osaka University, Osaka, Japan in 1989. From 1970 to 1979 , he was an Engineer at Xi'an Rectier Factory. Since 1982, he has been a Lecturer at Xi'an Jiaotong University, where he is also currently a Professor. He is the author and coauthor of more than 150 technical papers and has led numerous government and industry-sponsored projects in the areas of power and industrial electronics. His research interests include power conversion systems, harmonic suppression, reactive power compensation, motor drives, power electronic integration, and active power filters. 